\title{
A Note on the Structure of Employee Withdrawal
}

\author{
TERry A. BeEhr \\ Illinois State University \\ AND \\ Nina Gupta \\ The University of Michigan
}

\begin{abstract}
Disenchanted employees may choose to withdraw from the organization in at least four ways, viz., psychological withdrawal, lateness, absenteeism, and turnover. There are reasons for assuming that these different forms of withdrawal may be interrelated either negatively or positively. This study attempts to determine the direction and strength of the relationships among the various forms of withdrawal. The sample consisted of 651 employees from all levels of five midwestern work organizations. Three methods of data collection were used: structured interviews, a search through the companies' personnel records, and supervisors' ratings. It was concluded that the four forms of withdrawal are related with one another positively and with low to moderate strength. Implications of these findings are discussed and suggestions for future research are offered.
\end{abstract}

Employee withdrawal from an organization can take many behavioral forms, including turnover, absenteeism, and lateness. It may also be psychological, however, i.e., loss of job involvement. Previous research has placed little emphasis on the nature of the relationships that exist among these withdrawal forms, although it is reasonable to assume that they would be empirically related. Two tenable but conflicting possibilities regarding such relationships can be delineated.

First, some forms of withdrawal may be positively related due to common antecedents such as unsatisfactory working conditions or job stress. The existence of a positive relationship between two forms of withdrawal-absenteeism and turnover-has been advocated by Herzberg, Mausner, Peterson, and Capwell (1957) and by Melbin (1961) who concluded that "high absenteeism ... appears to be an earlier sign,

This research was partially supported by Grant No. 92-26-72-35 from the Manpower Administration of the U. S. Department of Labor. Researchers undertaking such projects under government sponsorship are encouraged to express their own judgment. Interpretations or viewpoints stated in this paper do not necessarily represent the official position or policy of the Department of Labor. The authors thank G. Douglas Jenkins, Jr., and Edward E. Lawler III for their many helpful comments on earlier drafts.

Requests for reprints should be sent to Terry A. Beehr, Illinois State University, Department of Psychology, DeGarmo Hall, Bloomington/Normal, Illinois 61761 . 
and turnover ... the dying stage of a long and lively process of leaving" (p. 15). Generalizing from this conclusion, all four forms of withdrawal may be different manifestations of the same general phenomenon.

Some forms of withdrawal may be related negatively, however, if one form of withdrawal substitutes for another. If employees were successfully coping with job stress by withdrawing psychologically, for example, they would not need to be physically absent from work. The assumption implicit in this argument is that a single withdrawal form may be a successful coping mechanism. Consistent with this approach, Hill and Trist (1955) have argued that absenteeism and turnover are alternative forms of withdrawal.

Most of the previous research in this area has focused only on the relationship between absenteeism and turnover (e.g., Kerr, Koppelmeir \& Sullivan, 1951; Hill \& Trist, 1955; Argyle, Gardner, \& Cioffi, 1958). Lyons' (1972) review concluded that the relationship between these two forms of withdrawal was positive and that there was tentative support for the notion that there is a progression of withdrawal, absenteeism being the lesser, and turnover the more serious, form.

The present study extends the previous research in two ways: (1) The definition of withdrawal is expanded to encompass a wider array of variables, viz., psychological withdrawal (low involvement) and lateness, as well as absenteeism and turnover; and (2) Multiple data sources are used to obtain information about the concepts investigated. Its purpose is likewise, two-fold: to determine (1) the direction and (2) the relative strength of the relationships among psychological distance, lateness, absenteeism, and turnover.

\section{METHOD}

\section{Sample and Data Sources}

Data were obtained from 651 employees from five midwestern organizations: A printing company $(N=173)$, two automobile accessories manufacturers $(N \mathrm{~s}=120$ and 124$)$, a research and development organization $(N=21)$, and four service departments of a hospital $(N=203)$. All supervisors at all levels below company president were included in the sample, while all levels of nonsupervisory personnel were sampled at rates varying from 25 to $100 \%$. The overall response rate was $72.9 \%$. The respondents to the interviews had the following characteristics: Mean age was 35 years, $51 \%$ were male, $68.5 \%$ were married, $79.8 \%$ were white, and $73 \%$ had at least a high school education.

Professional interviewers from the Survey Research Center of The University of Michigan conducted 90-minute structured interviews during nonwork hours, usually in the employees' homes. Data were also collected from all five companies' personnel records on absenteeism prior to 
the interview. In addition, for the hospital and the two automotive suppliers, personnel data were obtained for a period of time subsequent to the interview. Finally, supervisors in the sample were asked to rate all their subordinates on lateness. Ratings for those subordinates who were also in the sample were used in the present study.

\section{Measures}

Absenteeism. Three measures of absenteeism were used in the present study. The first, an interview measure of absenteeism $\left(\bar{X}=1.55, s^{2}=\right.$ 0.54 , range $=1-5$ ) during the month prior to the interview, consisted of three items, e.g., "Aside from any paid vacation and holidays, how many days of scheduled work have you missed in the past month?" Second, a measure of absenteeism from personnel records of the five organizations was obtained for the same month $\left(\bar{X}=1.09, s^{2}=2.12\right.$, range $\left.=0-9\right)$. Third, recorded absenteeism data from three of the organizations for 6 months subsequent to the interview $\left(\bar{X}=.83, s^{2}=.71\right.$, range $\left.=0-5\right)$ were averaged to provide a mean monthly rate of absenteeism subsequent to the interview. The recorded absenteeism measures included excused and unexcused absences for which employees were given sick leave or vacation, but did not include absences deemed to be clearly nonvoluntary (e.g., jury duty). A measure of frequency rather than duration of absence was preferred since the former appears to be a better measure of absenteeism within a psychological framework (e.g., Metzner \& Mann, 1953; Huse \& Taylor, 1962; White, 1960; Nicholson, Brown, \& ChadwickJones, 1976; Macy \& Mirvis, 1976).

Turnover. As with absenteeism, an effort was made to measure voluntary rather than involuntary turnover. Macy and Mirvis (1976) cite as examples of involuntary turnover retirement, permanent layoffs, and death. Two measures of turnover were obtained in the present study. The first was a one-item interview measure of intention to turn over $(\bar{X}=4.04$, $s^{2}=2.14$, range $\left.=1-5\right)$ : "Taking everything into consideration, how likely is it that you will make a genuine effort to find a new job with another employer within the next year?" (from Mangione, 1973). Possible responses ranged from "Not at all likely" to "Very likely." Second, recorded voluntary turnover $\left(\bar{X}=1.17, s^{2}=.15\right.$, range $\left.=1-2\right)$ during the 23 months subsequent to the interview was ascertained from three of the organizations (the hospital and the two automobile suppliers). ${ }^{1}$

Lateness. Two measures of lateness were available. The first, an inter-

\footnotetext{
${ }^{1}$ Classification of turnover as voluntary or involuntary was provided by the organization. Most of the cases classified as involuntary were relatively clear-cut, e.g., deaths, serious illness, and retirement, and there were only a small number of cases where the organizational classification was open to question. Therefore, the authors decided to adopt the organization's classification in the study.
} 
view index $\left(\bar{X}=1.57, s^{2}=.49\right.$, range $\left.=1-5\right)$, consisted of two items (see Quinn \& Shepard, 1974), e.g., "During the last 2 weeks, how many days did you arrive at work late?" The second measure of lateness was a supervisory rating $\left(\bar{X}=1.98, s^{2}=1.66\right.$, range $\left.=1-7\right)$ on a 7-point, semantic differential scale ranging from "always arrives on time" to "always late."

Low involvement. Involvement was measured with one interview item $\left(\bar{X}=2.94, s^{2}=.85\right.$, range $\left.=1-5\right)$ from Patchen (1965): "Some people are completely involved in their job-they are absorbed in it night and day. For other people, their job is simply one of several interests. How involved do you feel in your job-very little, slightly, moderately, or strongly involved?" The reverse score from this item constituted the low involvement index.

\section{RESULTS}

There is evidence of at least moderate validity of the measures, since nearly all correlations (Table 1) among indices of the same construct are

TABLE 1

Product-moment Correlations among Different Forms of Withdrawal ( NS IN Parentheses) $)^{n}$

\begin{tabular}{llllllll}
\hline & 1 & 2 & 3 & 4 & 5 & 6 & 7 \\
\hline
\end{tabular}

1. Low involvement (interviews)

2. Self-reported lateness $\quad .07$ (interviews)

3. Supervisor's ratings of lateness

4. Self-reported absenteeism (interviews)

(638) (613) (281)

5. Recorded absenteeism, one month prior to interview (personnel records)

$\begin{array}{llll}.16^{* *} & .19^{* *} & .28^{* *} & .38^{* *} \\ (528) & (523) & (238) & (525)\end{array}$

6. Recorded absenteeism, monthly rate for 6 -months subsequent to interview (personnel records)

7. Turnover intent (interviews)

8. Recorded voluntary turnover

$.14 * \quad .14$
(personnel records)

"The number of employees for whom data were available through any particular data source varied from one data source to another. Pair-wise deletion of missing cases was used in the calculation of correlations. As a result, the Ns vary in the table. 
stronger than correlations among indices measuring different constructs (Campbell \& Fiske, 1959). The only exceptions were due to strong correlations of the supervisor ratings of lateness with the absenteeism variables.

All of the correlations in Table 1 are positive, and 24 of the 28 correlations are statistically significant. The four nonsignificant correlations involved the lateness variables. The self-report measure of lateness was not related to the 6-month absenteeism index or to low involvement; the supervisory ratings of lateness were not related to either turnover index. In general, however, there is support for a tentative conclusion that all forms of employee withdrawal are related positively. The median correlation between measures of absenteeism and measures of psychological distance, lateness, and turnover were .165 for turnover, . 16 for low involvement, and .15 for lateness. Overall, these relationships were low to moderate.

\section{DISCUSSION}

The results clearly establish a positive relationship among most withdrawal responses; there exists a nucleus of withdrawal events that occur in concert. It is, therefore, especially important that the organization discover the causes of employee withdrawal; not only does an organization with employee problems need to concern itself with the employees' lack of involvement, but it has to contend with the problems of high absenteeism, turnover, and lateness at the same time.

Similarly, from the employee's perspective, the salience of the issue of causes and consequences of withdrawal is magnified if, as the results suggest, there exists a nucleus of withdrawal behaviors. An assumption underlying the argument that the different forms of withdrawal were alternatives to each other was that one form of withdrawal would be sufficient to serve as a coping mechanism for whatever aversive situation led to withdrawal in the first place. Since the withdrawal forms do not appear to be alternatives, however, it may be that they do not succeed in coping with the discomfort associated with the work environment. If they do not, then these withdrawal responses may be detrimental to the organization without providing much help to the individual.

The strengths of the relationships among withdrawal forms were only low to moderate. One explanation of these results is that while all forms of withdrawal may manifest themselves together, their relative severity may be somewhat varied depending on their other correlates. Turnover, for example, is greatly influenced by environmental variables such as labor market conditions (Behrend, 1953), while other forms of withdrawal are less affected. To the extent that the forms of withdrawal are influenced by 
events other than the simple desire to get away from the organization, the relationships among them will be limited.

These less than perfect conceptual relationships in the present study may be further attenuated because of certain weaknesses inherent in the data themselves. For example, the data were primarily cross-sectional in nature, so that idiosyncratic temporal influences would go undetected. Second, data for all the variables were not available for all employees. Information on voluntary turnover, for example, was limited to employees of only three of the five organizations. Third, while an attempt was made to classify absenteeism and turnover in terms of their voluntary nature, such a distinction was not made for lateness. In addition, the voluntary absenteeism and turnover classifications were made on the basis of personnel records, which may not have reflected the true nature of the variables.

The weakest support for the conclusion that withdrawal forms are related positively concerned the lateness indices. There are three possible reasons for this. First, it may be that lateness is not a significant manifestation of withdrawal for most employees; once employees decide to go to work, they may not see much difference between arriving on time or arriving late. Second, it may be that in the particular organizations investigated in the present study greater negative sanctions were attached, either implicitly or explicitly, to lateness than to other forms of withdrawal. A third and related reason, is that the forces influencing lateness may be different in nature from those influencing the other forms of withdrawal. For example, if employees are late, the consequences of this behavior may become obvious, in the form of supervisory disapproval immediately upon their late arrival. Because such negative sanctions are administered immediately for lateness, it might not constitute a very successful coping mechanism.

In summary, it is concluded that a positive relationship exists among the various types of employee withdrawal. There is reason for confidence in this conclusion because of the two particular strengths of the present study, i.e., the inclusion of four types of employee withdrawal (turnover, absenteeism, lateness, and low involvement) rather than the typical two, and the use of multiple sources of measurement.

A fruitful line of future research on this topic would focus on the nature of these relationships over time. Obviously, turnover is the final withdrawal response, but it would be beneficial to examine whether the other forms of withdrawal follow a sequential pattern. Is psychological withdrawal the first signal, for example, that the employee is becoming disenchanted from the work environment? Time-series data are needed to answer such questions. 


\section{REFERENCES}

Argyle, M., Gardner, G., \& Cioffi, I. Supervisory methods related to productivity, absenteeism and labor turnover. Human Relations, 1958, 11, 23-40.

Behrend, $\mathrm{H}$. Absence and turnover in a changing economic climate. Occupational Psychology, 1953, 27, 69-79.

Campbell, D. T., \& Fiske, D. W. Convergent and discriminant validation by the multitraitmultimethod matrix. Psychological Bulletin, 1959, 56, 81-105.

Herzberg, F., Mausner, B., Peterson, R. O., \& Capwell, D. F. Job attitudes: Review of research and opinion. Pittsburgh: Psychological Service of Pittsburgh, 1957.

Hill, J. M., \& Trist, E. L. Changes in accidents and other absences with length of service. Human Relations, 1955, 8, 121-152.

Huse, E. F., \& Taylor, E. K. Reliability of absence measures. Journal of Applied Psychology, 1962, 46, 159-160.

Kerr, W. A., Koppelmeier, G. J., \& Sullivan, J. J. Absenteeism, turnover, and morale in a metals fabrication factory. Occupational Psychology, 1951, 25, 50-55.

Lyons, T. F. Turnover and absenteeism: A review of relationships and shared correlates. Personnel Psychology, 1972, 25, 271-281.

Macy, B. A., \& Mirvis, P. H. A methodology for assessment of quality of work life and organizational effectiveness in behavioral-economic terms. Administrative Science Quarterly, 1976, 21, 212-226.

Mangione, T. W. Turnover-Some psychological and demographic correlates. In R. P. Quinn \& T. W. Mangione (Eds.), The 1969-70 survey of working conditions: Chronicles of an unfinished enterprise. Ann Arbor: Survey Research Center, 1973.

Melbin, M. Organizational practice and individual behavior: Absenteeism among psychiatric aides. Americal Sociological Review, 1961, 26, 14-23.

Metzner, H., \& Mann, F. C. Employee attitudes and absence. Personnel Psychology, 1953, $6,467-485$.

Nicholson, N., Brown, C. A., \& Chadwick-Jones, J. K. Absence from work and job satisfaction. Journal of Applied Psychology, 1967, 61, 728-737.

Patchen, M. Some questionnaire measures of employee motivation and morale. Monograph No. 41. Ann Arbor: Institute for Social Research, 1965.

Quinn, R. P., \& Shepard, L. J. The 1972-73 quatity of employment survey: Descriptive statistics with comparison data from the 1969-70 survey of working conditions. Ann Arbor: Survey Research Center, 1974.

White, B. L. Job attitudes, absence from work, and labour turnover. Personnel Practices Bulletin, 1960, 16, 18-23.

ReCeived: August 1, 1977. 